KOWALSKI, L.H. et al. Salmoneloses emergentes de origem aviária. PUBVET, Londrina, V.5, N. 34, Ed. 181, Art. 1221, 2011.

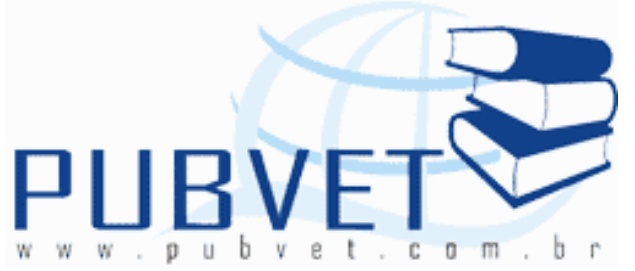

PUBVET, Publicações em Medicina Veterinária e Zootecnia.

\title{
Salmoneloses emergentes de origem aviária
}

Luciana Helena Kowalski ${ }^{1}$, Sergio Rodrigo Fernandes ${ }^{2}$,

Ana Paula Silva ${ }^{3}$, Raquel Cristina Bredt ${ }^{4}$, Thiago Augusto $\mathrm{Cruz}^{5}$, Marina

Gabriela Berchiol da Silva ${ }^{6}$

${ }^{1}$ Acadêmica de Medicina Veterinária da Universidade Federal do Paraná.

2 Doutorando do Programa de Pós-Graduação em Ciências Veterinárias da Universidade Federal do Paraná. Bolsista da CAPES/REUNI.

3 Médica Veterinária Residente de Doenças Infecciosas da Universidade Estadual de Londrina.

${ }^{4}$ Acadêmica de Medicina Veterinária da Universidade Federal do Paraná.

${ }^{5}$ Acadêmico de Zootecnia da Universidade Federal do Paraná.

${ }^{6}$ Doutoranda do Programa de Pós-Graduação em Zootecnia da Universidade Estadual Paulista. Bolsista CNPq.

\section{Resumo}

As bactérias do gênero Salmonella $s p$. são bastonetes da família Enterobacteriaciae, anaeróbios facultativos e parasitas intracelulares facultativos com distribuição cosmopolita. São considerados patógenos de grande importância tanto para animais como para humanos. Na indústria avícola, as salmonelas geralmente não causam enfermidades nas aves, porém estão envolvidas em toxinfecções alimentares em humanos e são consideradas de grande importância para saúde pública. A principal fonte de transmissão para humanos é o consumo de ovos, seguido da carne de frango. O controle desta doença é complexo devido a sua ampla distribuição, 
KOWALSKI, L.H. et al. Salmoneloses emergentes de origem aviária. PUBVET, Londrina, V.5, N. 34, Ed. 181, Art. 1221, 2011.

tornando-se necessário a adoção de medidas preventivas, pois uma vez presente na cadeia de produção da indústria avícola, o manejo sanitário para controle da Salmonella sp. é oneroso. Em geral os sinais clínicos da salmonelose estão associados ao trato gastrointestinal, porém pode ocorrer infecção sistêmica com casos de morte. Os prejuízos são elevados tanto para a indústria avícola quanto para a saúde pública, sendo que a melhor forma de reduzir os gastos relacionados à enfermidade é adotando medidas preventivas e não curativas. O objetivo desta revisão é mostrar a importância da salmonelose de origem aviária na saúde pública.

Palavras-chave: indústria avícola, Salmonella sp.; saúde pública; toxinfecções alimentares

\section{Emergent salmonellosis of avian origin}

\section{Abstract}

The genus Salmonella are rod-shaped facultative anaerobes enterobacteria that are obligatory intracellular parasites and worldwide distributed. These pathogens are considered of great importance for animals as for humans. In broiler industry, Salmonella normally cause no harm to poultry, but are involved in foodborne diseases in humans and represent a significant public health problem. The main source of transmission to humans is the consumption of eggs, followed by bovine meat and chicken. Control of this disease is complex because of its wide distribution, making it necessary to adopt preventive measures, because once present in the production chain of poultry industry, the health management for control of Salmonella is expensive. In general, clinical signs of salmonellosis are associated with the gastrointestinal tract, but systematic infection can occur with death. The losses are high for both poultry industry and for public health, and the best way to reduce costs are related to the disease is by adopting preventive measures rather than curative measures. The objective of this review is to show the importance of avian Salmonella in public health.

Keywords: poultry industry, Salmonella sp.; public health; foodborne disease 
KOWALSKI, L.H. et al. Salmoneloses emergentes de origem aviária. PUBVET, Londrina, V.5, N. 34, Ed. 181, Art. 1221, 2011.

\section{INTRODUÇÃO}

A salmonelose é uma zoonose e, ainda, de maior importância na indústria avícola. (Rossi et. al., 2007). As aves podem ser consideradas o ponto central na manutenção da enfermidade, uma vez que é difícil a deteç̧ão das bactérias e nem mesmo no abate há sinais da presença das mesmas, o que torna os produtos de origem destes animais potenciais fontes de toxinfecções alimentares (Borsoi et. al., 2010).

A maioria dos casos de gastroenterites em humanos que são causadas por Salmonella sp. de origem alimentar não necessita de internamento do paciente, com isso há uma subnotificação de enfermidade. No Brasil, estimase que apenas $10 \%$ das salmoneloses humanas são notificadas (Shinohara et. al., 2008). Nos Estados Unidos e na Europa foi implantado uma rede network de notificação desta enfermidade, e há previsão de que o mesmo sistema seja implantado nos países da América Latina (Fai et. al., 2011).

Dentre as salmonelas de maior importância estão a $S$. Enteretidis, S. Typhimurium e $S$. Heidelberg, as três são responsáveis pelo paratifo aviário, sendo a primeira uma das mais recentes e de maior importância em saúde pública (Sterzo et. al., 2008).

A Salmonella $s p$. gera grandes perdas econômicas para avicultura e, desta forma, é um entrave na avicultura atual. O objetivo desta revisão é mostrar a importância da salmonelose na indústria avícola e na saúde pública.

\section{NOMENCLATURA E TAXONOMIA DO GÊNERO Salmonella sp.}

Os primeiros relatos da bactéria Salmonella $s p$. foram realizados em 1880 por Erberth. Em 1885 Smith e Salmon isolaram a bactéria e atribuíram o nome de Bacillus cholera suis, sendo posteriormente associada a casos de doenças transmitidas por alimentos. Apenas em 1900 Lignières classificou o gênero Salmonella sp. (Wray e Wray, 2003).

O gênero Salmonella sp. pertence à família Enterobacteriaciae, são bastonetes de 0,5 a 0,7 por 1 a 3 micrômetros, móveis por flagelos, não 
KOWALSKI, L.H. et al. Salmoneloses emergentes de origem aviária. PUBVET, Londrina, V.5, N. 34, Ed. 181, Art. 1221, 2011.

esporulados. São gram negativos, anaeróbios facultativos e parasitas intracelulares facultativos (Bohez, 2008; Tahergorabi et. al., 2010).

A nomenclatura das salmonelas ainda gera muitas dúvidas, pois cientistas não entraram em comum acordo de como se referir a esse gênero. O padrão de nomenclatura atualmente melhor aceito é o proposto por Kauffmann-White, padrão também adotado pela Organização Mundial de Saúde (OMS) (Silva et. al., 2010). Segundo a nomenclatura de KauffmannWhite, o gênero Salmonella $s p$. consiste em apenas duas espécies: Salmonella enterica e Salmonella bongori, a primeira é subdividida em seis subespécies, as quais são subdivididas em diversos sorotipos. Já foram identificados aproximadamente 2.610 sorotipos, a S. enterica subsp. enterica apresenta o maior número de sorotipos (Guibourdenche et.al., 2010; Tabela 1). Existe, ainda, a proposta de incluir uma terceira espécie, a S. subterrânea, porém esta mudança depende, principalmente, do Instituto Pasteur em Paris, considerado centro de referência em pesquisa para a nomenclatura do gênero Salmonella sp., da OMS, do Centro de Controle e Prevenção de Doenças (CDC) dos Estados Unidos e da Sociedade Americana de Microbiologia (ASM) (Back, 2010).

Para exemplificar a forma correta de descrever esta bactéria, segue um exemplo: Salmonella enterica subespécie enterica sorotipo Pullorum (Tabela 2). Porém, podemos encontrar em literaturas abreviações desta nomenclatura, utilizando apenas o gênero e o sorotipo, neste exemplo ficaria Salmonella Pullorum. 
KOWALSKI, L.H. et al. Salmoneloses emergentes de origem aviária. PUBVET, Londrina, V.5, N. 34, Ed. 181, Art. 1221, 2011.

Tabela 1 - Classificação atual do gênero Salmonella sp.

Espécie Salmonella e subespécies $\begin{gathered}N^{\circ} \text { de } \\ \text { sorotipos }\end{gathered}$

S. enterica

S. enterica subsp. enterica (I)

S. enterica subsp. salamae (II)

$1547 \quad$ Animais de sangue quente. meio ambiente.

S. enterica subsp. arizonae (IIIa)

S. enterica subsp. diarizonae (IIIb) 341 sangue quente e meio ambiente.

S. enterica subsp. houtenae (IV)

S. enterica subsp. indica (VI)

S. bongori Animais de sangue frio, sangue quente e meio ambiente.

Animais de sangue frio,

Animais de sangue frio e meio ambiente.

Animais de sangue frio e meio ambiente.

Animais de sangue frio e meio ambiente.

TOTAL 2610

Fonte: adaptado de Brenner et al. (2000) e Guibourdenche et al. (2010)

Tabela 2 - Nomenclatura das salmonelas

\begin{tabular}{|c|c|}
\hline Posição Taxonômica & Nomenclatura \\
\hline Gênero (Itálico)........ & Salmonella \\
\hline Espécie (Itálico)... & $\begin{array}{l}\text { - enterica, que inclui subespecies } \\
\text { I, II, IIIa, IIIb, IV e VI } \\
\text { - bongori }\end{array}$ \\
\hline orotipo (Letra maiúscula e sem itál & Gallinarum e Pullorum \\
\hline
\end{tabular}

Fonte: adaptado de Brenner et al. (2000)

\section{EPIDEMIOLOGIA E SAÚDE PÚBLICA}

O gênero Salmonella $s p$. contém um número grande de sorotipos, sendo muitos deles relacionados à enfermidades em animais e em humanos (Yan et. al., 2003). Esta bactéria é uma das principais envolvidas em surtos 
KOWALSKI, L.H. et al. Salmoneloses emergentes de origem aviária. PUBVET, Londrina, V.5, N. 34, Ed. 181, Art. 1221, 2011.

alimentares (Greig e Ravel, 2008), sendo capaz de produzir infecções graves. Estima-se que $96 \%$ dos casos de salmonelose em humanos ocorre pelo consumo de produtos de origem animal (Tahergorabi et. al., 2011). As principais infecções em humanos causadas por esta bactéria são as gastroenterites, porém em poucos casos pode ocorrer uma infecção sistêmica, extra-intestinais, graves (Yan et. al., 2003).

A salmonela pode ser encontrada em carnes, ovos, leite, vegetais, frutas, répteis, água, animais silvestres, pasta de amendoim, produto consumido amplamente nos EUA e estudos recentes mostram surtos envolvendo o consumo do mesmo (Conceição et. al., 2008; Boxrud, 2010; Liu et. al., 2011). Os surtos de salmoneloses ocorrem em maior freqüência pelo consumo de produtos avícolas, como, carne de frango e ovos contaminados, sendo o principal veículo os ovos (Yan et. al., 2003; Pinto e Silva, 2009). Outro fator importante da disseminação desta bactéria é a manipulação inadequada de alimentos durante seu preparo, acarretando em contaminação cruzada de alimentos (Kottwitz et. al., 2008).

Uma das principais infeç̧ões que comprometem a avicultura são as salmoneloses causadas por Salmonella enterica subspécie enterica sorotipo Pullorum, S. enterica subspécie enterica sorotipo Gallinarum, Salmonella enterica subspécie enterica sorotipo Typhimurium, Salmonella enterica subspécie enterica sorotipo Enteritidis (Buchala et. al., 2006). As duas primeiras são sorotipos espécie-específicas, ou seja, acometem apenas as aves, enquanto as demais acometem aves e humanos.

A Salmonella enterica ocasiona perdas em produção na indústria avícola, causando a diminuição no desempenho e até morte das aves. Além disso, é um problema para saúde publica, onde consumidores de carne e ovos contaminados podem apresentar toxinfecções alimentares (Redmond et. al., 2009; Silva e Pinto, 2009).

As salmonelas paratíficas são as de maior importância na avicultura, pois estas são as causadoras de toxinfecções em humanos (Tessari et al., 2003). A Salmonella Enteritides, principal salmonelose paratífica, foi 
KOWALSKI, L.H. et al. Salmoneloses emergentes de origem aviária. PUBVET, Londrina, V.5, N. 34, Ed. 181, Art. 1221, 2011.

reconhecida como problema no Brasil apenas em 1993 (Silva e Duarte, 2010), e desde então tem sido o sorotipo mais frequente em produtos avícolas.

As salmoneloses estão entre os problemas de maior prevalência na avicultura, porém quando não há um bom programa de controle sanitário estas bactérias não são reconhecidas. As principais fontes de infecção para aves comerciais são a introdução de lotes contaminados, o ambiente de produção e a ração contaminados (Tessari et al., 2003). Animais jovens são os mais afetados pela enfermidade, pois ainda não tem sistema imune competente para combater o agente e a microbiota intestinal ainda não está totalmente formada. Animais adultos têm importância na prevalência do agente, pois, normalmente, são portadores assintomáticos (Sadeyen et al., 2004). Tessari et. al. (2003) demonstraram que as matrizes tem fundamental importância na manutenção da doença, pois elas são capazes de transmitir de forma vertical o agente à sua progênie.

Kottwitz et. al. (2010) mostraram que $45 \%$ dos surtos de salmonelose estão associados ao consumo de ovos. Pinto e Silva (2009) relataram que há maior frequencia de contaminação por Salmonella sp. em ovos estocados em ambiente com temperatura de $30^{\circ} \mathrm{C}$ comparado a ambiente com temperatura de $8^{\circ} \mathrm{C}$. A prevalência de Salmonella $s p$. em casca de ovos é superior quando os mesmo permanecem refrigerados sem adequada higienização prévia, pois a refrigeração apenas diminui a atividade bacteriana. Os autores concluíram que para que os ovos não sejam contaminados por Salmonella sp. e, dessa forma, estejam aptos a comercialização, estes devem apresentar baixos índices de defeitos de casca, devem ser lavados e comercializados sob refrigeração. Raghiante et. al. (2010) observaram tempo médio de 2 horas para penetração da $S$. Heidelberg em ovos, portanto a lavagem industrial de ovos deve ser realizada antes de haver a penetração.

Kottwitz et. al. (2008) não encontraram Salmonella Enteritidis em ovos comerciais, porém há estudos que demonstram que $50 \%$ das contaminações 
KOWALSKI, L.H. et al. Salmoneloses emergentes de origem aviária. PUBVET, Londrina, V.5, N. 34, Ed. 181, Art. 1221, 2011.

de ovos ocorrem por este agente. Os autores atribuem esta diferença a provável comercialização ilegal de ovos caipiras, que não são higienizados da mesma forma que os ovos comerciais.

A segunda maior fonte de toxinfecção alimentar em humanos é a carne de frango. O controle da Salmonella $s p$. na indústria avícola é oneroso devido a sua complexa epidemiologia, uma vez que galpões encontram-se contaminados por bactérias trazidas por pintos de um dia ou remanescentes de lotes anteriores, o que favorece a contaminação de carcaças de forma indireta (Boni et. al., 2011).

A transmissão vertical para pintinhos destinados à criação para corte é uma das principais fontes de infecção, podendo ocorrer de forma direta do albúmen do ovo para o pintinho, como na hora da eclosão pelo contato com a casca contaminada (Pinto et. al., 2009). Zancan et. al. (2000) e Rocha et. al. (2003) mostraram que a caixa de transporte de pintinhos de um dia também podem ser fonte de contaminação destes animais.

Lopes et. al. (2007) mostraram que a contagem de microorganismos em abatedouros não diminuiu após a passagem das carcaças pelos tanques, na água do pre-chiller e chiller. Isso demonstra a necessidade de novos estudos para a redução da contaminação de carcaças por Salmonella sp. e a fiscalização de abatedouros, visando averiguar irregularidades na higienização de equipamentos e nos procedimentos de abate, os quais são fontes de contaminação. Conforme Boni et al. (2011), aproximadamente $11 \%$ das carcaças de frango são contaminadas por Salmonella sp., devido a este elevado resultado faz-se necessário um programa sanitário específico para controle da Salmonella sp., pois a maioria dos sorotipos são potencialmente patogênicos ao homem (Tessari et. al., 2008).

\section{PATOGENIA E IMUNIDADE À Salmonella sp. EM AVES E HUMANOS}

O conhecimento sobre a resposta imune à Salmonella $s p$. advém de estudos com inoculação experimental de $S$. Typhimurium em camundongos, 
KOWALSKI, L.H. et al. Salmoneloses emergentes de origem aviária. PUBVET, Londrina, V.5, N. 34, Ed. 181, Art. 1221, 2011.

sendo os resultados obtidos extrapolados para aves e para outros sorotipos (Carvajal et al., 2008).

Animais jovens apresentam baixa capacidade de resposta imune a infecções por Salmonella sp., o que se deve, principalmente, a formação incompleta da primeira linha de defesa na parede intestinal, como também do sistema imunológico do indivíduo (Wray e Wray, 2003).

A principal via de infecção para aves e humanos é a oro fecal. Quando há ingestão de Salmonella sp., ela sofrerá ação da imunidade inata, em que ocorre a ação de ácido gástrico do estômago, motilidade intestinal, e ação da flora microbiana do trato intestinal. Passando esta primeira barreira, a bactéria inicia rapidamente a colonização do trato intestinal e se liga a receptores (Wray e Wray, 2003). Adesão da bactéria a parede intestinal depende de diversos fatores de associação, como: Lipopolissacarídeos (LPS), flagelos, fímbrias e proteína de membrana externa, porém o papel destes fatores na patogênese permanece controverso (Mizumoto et al., 2005). Em seguida, a bactéria consegue penetrar na parede intestinal, o que resulta em resposta pró-inflamatória (Shaughnessy et al., 2009) e estimula a ação dos heterófilos, no caso de aves, e neutrófilos, em humanos, no local da infecção. Assim, há um evidente aumento das citocinas e quimiocinas IL-1b, IL-6, CXCLi1 e CXCLi2 (Chappell et al., 2009; Shaughnessy et al., 2009). No momento da invasão a bactéria apresenta sistemas de secreção tipo III SPI1-TTSS, e estudo realizado por Wigley et al. (2002) mostra que este sistema contribui para virulência da bactéria.

A resposta inflamatória ocasiona a liberação de prostaglandinas e, com isso, há um aumento da secreção de água, bicarbonatos e cloretos no lúmen intestinal. Também há liberação de substâncias vasoativas que aumentam a permeabilidade dos vasos da mucosa intestinal. Estas duas respostas inflamatórias levam ao quadro de diarréia (Baldy e Amato Neto, 1989).

A Salmonella $s p$. pode invadir os macrófagos, motivo pela qual é considerada parasita intracelular facultativo (Bohez et al., 2008), e por meio dos macrófagos é tranportado via linfática para outros órgão, como o fígado, 
KOWALSKI, L.H. et al. Salmoneloses emergentes de origem aviária. PUBVET, Londrina, V.5, N. 34, Ed. 181, Art. 1221, 2011.

baço e aparelho reprodutivo. Este processo é fundamental para a continuidade da infecção, portanto, para bactéria assegurar este processo ela apresenta o sistema de secreção tipo III SPI2-TTSS, que vai assegurar sua sobrevivência e proliferação nos macrófagos (Moura, 2007; Andrade et. al., 2008; Chappell et. al., 2009). A resistência do hospedeiro à infecção sistêmica pela Salmonella sp. é multifatorial, porém, o ponto chave á nesta fase de invasão de macrófagos (Wigley et al., 2004; Wigley et al., 2006; Tabela 3).

Os macrófagos estimulados pelo IFN- $\gamma$ (citocina pró-inflamatória) ativam a enzima óxido nítricosintase que catalisa a produção de óxido nítrico a partir de I-arginina. O óxido nitroso é tóxico principalmente para bactérias que ficam dentro de macrófagos, como é o caso da Salmonella sp. (Moura, 2007).

Apenas a resposta humoral não é capaz de conter a infecção (Desmidt et al., 1998), assim inicia-se o processo de "clearance" no baço e fígado. Este processo é realizado por mecanismos imuno-dependentes de anticorpos, iniciando-se com as células $T$ helper-1 e com o aumento dos níveis de interferon- $\square$ entre o $14^{\circ}$ e $28^{\circ}$ dia. Após ocorre a opsonização e a fagocitose, quando as salmonelas são liberadas extracelularmente (Roitt et al., 2003; Chappell et. al., 2009), assim o agente é eliminado.

Quando o agente não consegue ser eliminado, o hospedeiro torna-se portador da doença. A bactéria permanece no fígado, baço e trato reprodutivo, de maneira que "entra em equilíbrio" com o organismo (Chappell et al., 2009). Nessas condições, apesar dos hospedeiros não apresentarem sinais clínicos, estes são disseminadores da doença, e continuam eliminando a bactéria, principalmente via fecal.

Em trabalhos realizados por Desmidt et al. (1998) e Sheela et al. (2003) com Salmonella Enteretidis, demonstrou-se que a IgA tem importante papel no início da infecção, pois esta protege o intestino contra a colonização da bactéria. 
KOWALSKI, L.H. et al. Salmoneloses emergentes de origem aviária. PUBVET, Londrina, V.5, N. 34, Ed. 181, Art. 1221, 2011.

Quando a bactéria é transportada pelos macrófagos para outros órgãos ela pode atingir o órgão reprodutivo de fêmeas, contaminado os ovos que a matriz produzirá e, consequentemente, a progênie. Esta contaminação ocorre na formação do folículo da gema no albúmen do oviduto, e também após a formação da casca, quando o ovo passa pela cloaca contaminada, sendo caracterizada como infecção vertical (Andrade et al., 2008). Miyamoto et. al. (2005) comprovaram que a infecção também pode ocorrer por via ascendente, ou seja, a bactéria pode invadir e colonizar o epitélio vaginal e infectar o oviduto e ovários, podendo causar infecção sistêmica. Os autores relataram que não há diminuição na produção de ovos após a contaminação da bactéria, porém os ovos produzidos são contaminados. A S. Enteritidis é a que apresenta maior tropismo pelo tecido reprodutivo. 
Tabela 3 - Interação entre Salmonella sp. e sistema imune das aves

\begin{tabular}{|c|c|c|c|c|c|}
\hline Fase & Ação & Sítio no hospedeiro & $\begin{array}{c}\text { Células hospedeiras } \\
\text { envolvidas }\end{array}$ & $\begin{array}{l}\text { Interação patógeno- } \\
\text { hospedeiro }\end{array}$ & $\begin{array}{c}\text { Fatores } \\
\text { patogênicos }\end{array}$ \\
\hline 1 & Invasão & $\begin{array}{l}\text { Trato gastrointestinal } \\
\text { (TGI) }\end{array}$ & Epitélio do TGI & $\begin{array}{l}\text { Sem reação } \\
\text { inflamatória. Invasão } \\
\text { da bactéria à parede do } \\
\text { intestino. }\end{array}$ & $\begin{array}{l}\text { Ausência de } \\
\text { flagelos. } \\
\text { Secreção tipo III } \\
\text { SPI1. }\end{array}$ \\
\hline 2 & $\begin{array}{l}\text { Infecção } \\
\text { sistêmica }\end{array}$ & $\begin{array}{l}\text { Intestino associado } \\
\text { ao tecido linfóide }\end{array}$ & $\begin{array}{c}\text { Macrófagos } \\
\text { Células dendríticas }\end{array}$ & $\begin{array}{l}\text { Absorção no TGI e } \\
\text { infecção sistêmica. } \\
\text { Invasão e replicação } \\
\text { nos macrófagos }\end{array}$ & $\begin{array}{l}\text { Secreção tipo III } \\
\text { SPI2 }\end{array}$ \\
\hline \multirow[b]{3}{*}{3} & Clearance & Baço e fígado & $\begin{array}{l}\text { Linfócitos T } \\
\text { Linfócitos B } \\
\text { Macrófagos }\end{array}$ & $\begin{array}{l}\text { Controle da replicação } \\
\text { pela Imunidade Inata } \\
\text { Clearance da infecção } \\
\text { pela Th-1. }\end{array}$ & \\
\hline & Morte & Sistêmico & $\begin{array}{l}\text { Macrófagos } \\
\text { Heterófilos }\end{array}$ & $\begin{array}{l}\text { Falha no controle da } \\
\text { replicação }\end{array}$ & $\begin{array}{l}\text { Secreção tipo III } \\
\text { SPI1 e SPI2, LPS e } \\
\text { toxina }\end{array}$ \\
\hline & Portador & $\begin{array}{l}\text { Fígado, baço e trato } \\
\text { reprodutivo }\end{array}$ & $\begin{array}{l}\text { Macrófagos } \\
\text { Linfócitos T }\end{array}$ & $\begin{array}{l}\text { Controle da replicação. } \\
\text { Parcial Clearance pela } \\
\text { resposta adaptativa. } \\
\text { Equilíbrio imunológico } \\
\text { entre resposta } \\
\text { adaptativa e modulação } \\
\text { do hospedeiro. } \\
\text { Imunossupressão. }\end{array}$ & $\begin{array}{l}\text { Secreção tipo III } \\
\text { SPI2 }\end{array}$ \\
\hline
\end{tabular}

Fonte: adaptado de Chappell et al. (2009) 
KOWALSKI, L.H. et al. Salmoneloses emergentes de origem aviária. PUBVET, Londrina, V.5, N. 34, Ed. 181, Art. 1221, 2011.

\section{SALMONELOSES EMERGENTES DE ORIGEM AVIÁRIA}

Os principais sorotipos de salmonelas de origem aviária estão listados na Tabela 4. Podem-se considerar recentes os surtos de salmoneloses, uma vez que iniciaram na década de 70 e apenas na década de 80 o principal sorotipo envolvido atualmente em surtos de salmonelose, o $S$. Enteritidis foi associado à toxinfecções alimentares. A S. Enteritidis fagotipo 4 é o predominante em aves e mais patogênico para seres humano (Back, 2010).

Tabela 4 - Salmonelas clínicas isoladas de produtos avícolas

\begin{tabular}{cc}
\hline Sorotipos & Frangos \\
\hline Kentucky & 30 \\
Enteritidis & 26 \\
Heidelberg & 21 \\
Thypimurium & 18 \\
Hadar & 9 \\
Senftenberg & 7 \\
Gallinarum & 5 \\
Thypimurium var. 5- & 5 \\
I 4,[5],12:i:- & 4 \\
Anatum & 3 \\
Infantis & 3 \\
Mbandaka & 3 \\
Agona & 2 \\
Anatum var. 15+ & 2 \\
Dublin & 2 \\
Johannesburg & 2 \\
Ohio & 2 \\
Schwarzengrund & 2 \\
Braenderup & 1 \\
Hartford & 1 \\
Javiana & 1 \\
Livingstone & 1 \\
Muenster & 1 \\
Oranienburg & 1 \\
Orion & 1 \\
Ouakam & 1 \\
Thompson & 1 \\
Worthington & 1 \\
I 4,[5],12:d:- & 1 \\
I 6,7:k:- &
\end{tabular}

Fonte: adaptado de CDC (2006) 
KOWALSKI, L.H. et al. Salmoneloses emergentes de origem aviária. PUBVET, Londrina, V.5, N. 34, Ed. 181, Art. 1221, 2011.

As salmonelas de maior importância na saúde pública (Tabela 5) não produzem sinais clínicos nas aves infectadas, ou seja, estes animais são portadores assintomáticos e transmissores da enfermidade. As salmonelas paratíficas, todas Salmonella enterica subspécie enterica exceto a S. arizonae, S. Pullorum e S. Gallinarum (todas salmonelas de importância em saúde pública), nas aves tem como principal via de infecção a oral, mas há relatos de via aerossóis (Wray e Wray, 2003; Back, 2010).

Tabela 5 - Seis sorotipos de Salmonella sp. de maior importância pelo consumo de frangos e ovos por humanos

\begin{tabular}{cc}
\hline Sorotipos & Humanos \\
\hline Enteritidis & 6.740 \\
Thypimurium & 5.917 \\
Heidelberg & 1.495 \\
Hadar & 275 \\
Kentucky & 123 \\
Senftenberg & 113 \\
\hline
\end{tabular}

Fonte: adaptado de CDC (2006)

Em aves jovens pode causar mortalidade, ocorrendo geralmente até a $3^{a}$ semana de vida, principalmente em infecções vertical, apresentando como sinais clínicos sonolência, diarréia, desidratação, diminuição da ingestão de comida, desuniformidade e empastamento de cloaca. Em animais adultos geralmente não há sinais clínicos, mas ocasionalmente pode haver anorexia, diarréia e diminuição da produção de ovos. O tratamento é realizado através da administração de antibiótico via parenteral em animais de 1 dia de idade, através do alimento ou da água (Wray e Wray, 2003; Back, 2010).

Em humanos as salmoneloses são divididas em tifóides (S. typhi) e não tifóides. A salmonela não tifóide causa, em geral, quadros de gastroenterites, também pode haver portadores assintomáticos, que acabam por ter papel na transmissão da doença. Podem também estar associadas a bacteremia e infecções focais como meningite e osteomielite, estes casos, porém, são mais raros e geralmente associados à pacientes 
KOWALSKI, L.H. et al. Salmoneloses emergentes de origem aviária. PUBVET, Londrina, V.5, N. 34, Ed. 181, Art. 1221, 2011.

imunocomprometidos, principalmente em pessoas com vírus da imunodeficiência humana (HIV). A via de infecção é oral, com a ingestão de no mínimo $10^{8}-10^{11}$ unidades formadoras de colônia (UFC). O período de incubação é de 2 - 72 horas e os sintomas são diarréia, anorexia, desidratação e prostração, sendo a diarréia o principal sintoma. O tratamento é realizado com terapia antimicrobiana, reidratação e isolamento do paciente (Pickering e Peter, 2000; Santos et. al., 2001; Wray e Wray, 2003; Gordon, 2008).

\section{DiAgnóstico, PREVEnÇão e CONTROLE}

O diagnóstico de salmoneloses é realizado, basicamente, pela identificação do agente por meio de várias técnicas, entre elas os métodos de cultura, PCR e ELISA são os mais utilizados. Além destas técnicas, há o imunoensaio, a separação imunomagnética e a ressonância de plasma de superfície, este último ainda utilizado apenas em pesquisa. Dentro de cada técnica há estudos de sistemas diferentes, objetivando-se obter um teste fácil e rápido (Leon-Velarde, 2004; Jaradat, 2004; Rall, 2005; Franchin et. al., 2006; Lan et. al., 2008; Penha et. al., 2008; Conceição, 2008; Löfström et. al., 2010).

$\mathrm{Na}$ avicultura a salmonelose geralmente não é tratada, pois os gastos com antibióticos são elevados e desnecessários, associado a isso, também há o desvantagem da resistência à antibióticos por parte da bactéria (Alambedji et. al., 2006; Bada- Ribeiro et. al., 2008; Duarte et. al., 2009; Dallal et. al., 2010; Souza et. al., 2010; Yildirim et. al., 2011). Estudos mostram que óleos essenciais, Lactobacillus spp., ácidos orgânicos, mananoligossacarídeos, extratos de plantas são eficientes para inibição da Salmonella sp. (Oliveira et. al., 2000; Santurio et. al., 2007; Bassan et. al., 2008; Barros et. al., 2009). Podem-se utilizar, também, prebióticos e probióticos como prevenção e controle da salmonelose em aves, porém os resultados em alguns trabalhos são favoráveis e outros mostram o contrário (Rossi et. al., 2007; Ribeiro et. al., 2007; Leandro et. al., 2010). Pesquisa 
KOWALSKI, L.H. et al. Salmoneloses emergentes de origem aviária. PUBVET, Londrina, V.5, N. 34, Ed. 181, Art. 1221, 2011.

realizada por Leandro et. al. (2010) mostrou que a inoculação de probióticos no ovo evita a colonização do papo e do ceco de pintos pela Salmonella Enteritidis e melhora o peso vivo aos 21 dias.

A prevenção é a melhor maneira de lidar com a doença, esta se inicia com medidas básicas de isolamento e biosseguridade das granjas, lembrando sempre que o alimento também é uma fonte de infecção importante (Hofer et. al., 1998; Freitas Neto et. al., 2008; Back, 2010). Outras formas de prevenção são relacionadas a manejos pós-granja, como por exemplo, nos abatedouros para evitar a contaminação de carcaças e, principalmente, a contaminação cruzada (Rückert et. al., 2009; Borsoi et. al., 2010). Em relação a principal fonte de infecção, os ovos, é necessário realizar a inspeção dos mesmos e não comercializá-los quebrados, proceder a limpeza e higienização correta da casca até 2 horas após a postura e mantê-los sob refrigeração (Raghiante et. al., 2010; Martelli e Davies, 2011).

Para o controle nas aves há vacinas inativadas e vacinas vivas, porém o uso é limitado, pois há dificuldade em diferenciar os anticorpos vacinais de anticorpos de infecção. Isso é importante, pois a Instrução Normativa/DAS n078 de 3 de Novembro de 2003 estabelece que as granjas devem ser livres de $S$. Gallinarum e $S$. Pullorum e livres ou controladas para $S$. Enteritidis e S. Typhymurium. Se uma granja for positiva para qualquer uma das 2 primeiras bactérias citadas, todos os animais devem ser sacrificados. No caso de avós, quando positivo para qualquer uma das quatro espécies, todos os animais devem ser sacrificados (Neto et. al., 2008; Back, 2010).

Estudo em desenvolvimento, com a aplicação de feixe de elétrons em produtos alimentícios com o objetivo de inativar a Salmonella sp.,. tem demonstrado como uma forma eficiente de controle do crescimento bacteriano (Tahergorabi, et. al., 2011). 
KOWALSKI, L.H. et al. Salmoneloses emergentes de origem aviária. PUBVET, Londrina, V.5, N. 34, Ed. 181, Art. 1221, 2011.

\section{IMPACTO ECONÔMICO DA SALMONELOSE}

As perdas econômicas associadas à infecções por Salmonella sp. são alvo de estudos, principalmente nos Estados Unidos, Canadá e Europa (Rubino, 1997). Porém, além das perdas econômicas, o número de pessoas infectadas que vão a óbito também devem ser consideradas. A OMS relata que em 2005 houve morte de aproximadamente 1,5 milhões de pessoas no mundo por consequência de enterites (Buzby e Roberts, 2009).

Estudo realizado pelo CDC nos Estados Unidos mostrou que são gastos com casos de enterites em humanos 210 dólares por consulta, 5.797 dólares por internação com infecção gastrointestinal, 16.441 dólares por internação com infecção invasiva e 4,63 milhões dólares por morte. As perdas totais geradas pela Salmonella sp. foi estimado em US \$2,8 bilhões de dólares por ano, e de aproximadamente 2.472 dólares por caso de infecção por Salmonella sp. (Adhikari et. al., 2004).

Estudo realizado na Califórnia mostrou que anualmente são gastos 5 milhões de dólares pelas indústrias de ovos com a Salmonella sp., este valor vem desde a prevenção até as perdas pela contaminação e infecção de ovos e aves pela bactéria (Kinde et al., 2001). Na indústria de carne, é estimado que se gaste 0,20 dólares por carcaça com prevenção, controle e perdas pela Salmonella sp. (Jensen et. al., 1998).

\section{CONCLUSÃO}

As salmoneloses geram altos prejuízos econômicos tanto para indústria avícola quanto para saúde publica. Para se evitar tais prejuízos a melhor forma é aplicar medidas preventivas e evitar que a bactéria se instale em propriedades e produtos avícolas, pois pode haver contaminação no processamento do alimento. As indústrias, tanto de carne de aves quanto de ovos, devem adotar medidas voltadas exclusivamente para a prevenção das salmonelas, visando evitar ao máximo a contaminação cruzada. Órgãos públicos devem adotar medidas para que sejam realizadas notificações de casos de salmoneloses, não somente para casos onde é necessário 
KOWALSKI, L.H. et al. Salmoneloses emergentes de origem aviária. PUBVET, Londrina, V.5, N. 34, Ed. 181, Art. 1221, 2011.

internamento do paciente, assim poderá ser identificado os focos de contaminação e tomadas medidas efetivas de eliminação do foco.

\section{REFERÊNCIAS BIBLIOGRÁFICAS}

ADHIKARI, B.; ANGULO, F.; MELTZER, M. Economic Burden of Salmonella Infections in the United States. Disponível

em:

<http://ageconsearch.umn.edu/bitstream/20050/1/sp04ad01.pdf> Acesso em: 22/04/2011

ANDRADE, M.A.; MESQUITA, A.J.; STRINGHINI, J.H.; PEDROSO, A.A.; LEANDRO, N.S.M.; CAFÉ, M.B.; MATTOS, M.S. Infecção experimental de embriões de frango de corte com Salmonella enterica sorovar Enteritidis fagotipo 4. Arquivo brasileiro de Medicina Veterinária e Zootecnia, v.60, n.5, p.1110-1117, 2008.

BACK, Alberto. Manual de doenças de aves. 2.ed. rev. e il. Cascavel, PR: Integração, 2010. 311p.

BADA-ALAMBEDJI, R.; FOFANA, A.; SEYDI, M.; AKAKPO, A.J. Antimicrobial resistance of Salmonella isolated from poultry carcasses in Dakar (Senegal). Brazilian Journal of Microbiology, v.37, p.510-515, 2006.

BALDY, J.L.S.; AMATO NETO, V. Doenças Transmissíveis. 3. ed. rev. e ampl. São Paulo: Sarvier, 1989. 929p.

BARROS, M.R.; ANDREATTI FILHO, R.L.; LIMA, E.T.; CROCCI, J.A. Avaliação in vitro da atividade inibitória de Lactobacillus spp., isolados do inglúvio e cecos de aves sobre Salmonella. Arquivo brasileiro de Medicina Veterinária e Zootecnia, v.61, n.4, p.863868, 2009.

BASSAN, J.D.L.; FLÔRES, M.L.; ANTONIAZZI, T.; BIANCHI, E.; KUTTEL, J. TRINDADE, M.M. Controle da infecção por Salmonella Enteritidis em frangos de corte com ácidos orgânicos e mananoligossacarídeo. Ciência Rural, Santa Maria, v.38, n.7, p.1961-1965, 2008.

BOHEZ, L.; GANTOIS, I.; DUCATELLE, R.; PASMANS, F.; DEWULF, J.; HAESEBROUCK, F.; VAN IMMERSEEL, F. The Salmonella Pathogenicity Island 2 regulator ssrA promotes reproductive tract but not intestinal colonization in chickens. Veterinary Microbiology, v.126, p.216-224, 2008.

BONI, H.F.K.; CARRIJO, A.S.; FASCINA, V.B. Ocorrência de Salmonella spp. em aviários e abatedouro de frangos de corte na região central de Mato Grosso do Sul. Revista Brasileira de Saúde e Produção Animal, Salvador, v.12, n.1, p.84-95, 2011.

BORSOI, A.; MORAES, H.L.S.; SALLE, C.T.P.; NASCIMENTO, V.P. Número mais provável de Salmonella isoladas de carcaças de frango resfriadas. Ciência Rural, Santa Maria, v.40, n.11, p.2338-2342, 2010.

BOXRUD, D. Advances in subtyping methods of foodborne disease pathogens. Food Biotechnology, v.21, p.137-141, 2010.

BRASIL. Instrução Normativa No 78, de 03 de Novembro de 2003

BRENNER, F. W.; VILLAR, R. G.; ANGULO, F. J.; TAUXE, R.; SWAMINATHAN, B. Salmonella nomenclature. Journal of Clinical Microbiology, v.38,n.7, p. 2465-2467, 2000.

BUCHALA, F.G.; ISHIZUKA, M.M.; MATHIAS, L.A.; BERCHIERI JÚNIOR, A.; CASTRO, A.G.M.; CARDOSO, A.L.S.P.; TESSARI, E.N.C.; KANASHIRO, A.M.I. Ocorrência de reação sorológica contra Salmonella Pullorum em aves de "fundo de quintal" do estado de São Paulo, Brasil. Arquivos do Instituto Biológico, São Paulo, v.73, n.1, p.1-5, 2006. 
BUZBY, J.C.; ROBERTS, T. The economics of enteric infections: Human foodborne disease costs. Gastroenterology, v.136, n.6, p. 1851-1862, 2009.

CARVAJAL, B.G.; METHNER, U.; PIEPERA, J.; BERNDTA, A. Effects of Salmonella enterica serovar Enteritidis on cellular recruitment and cytokine gene expression in caecum of vaccinated chickens. Vaccine, v.26, p.5423-5433, 2008.

CENTERS OF DIASES CONTROL AND PREVENTION (CDC), Salmonella Annual Summaries, 2006, disponível em: <http://www.cdc.gov/ncidod/dbmd/phlisdata/salmonella.htm> Acesso em: $15 / 04 / 2011$

CHAPPELL, L.; KAISER, P.; BARROW, P.; JONES, M. A.; JOHNSTON, C.; WIGLEY, P. The immunobiology of avian systemic salmonellosis. Veterinary Immunology and Immunopathology, v.128, p.53-59, 2009.

CONCEIÇÃO, R.C.S.; MOREIRA, A,N.; RAMOS, R.J.; GOULARTE, F.L.; CARVALHAL, J.B.; ALEIXO, J.A.G. Detection of Salmonella sp in chicken cuts using immunomagnetic separation. Brazilian Journal of Microbiology, v.39, p.173-177, 2008.

DESMIDT, M.; DUCATELLEA， R.; MASTB， J.; GODDEERISB， B.M.; KASPERSC， B.; HAESEBROUCKA, F. Role of the humoral immune system in Salmonella Enteritidis phage type four infection in chickens. Veterinary Immunology and Immunopathology, v.63, p.355-367, 1998.

DUARTE, D.A.M.; RIBEIRO, A.R,; VASCONCELOS, A.M.M.; SANTOS, S.B.; SILVA, J.V.D.; ANDRADE, P.L.A.; FALCÃO, L.S.P.C.A. Occurrence of Salmonella spp. in broiler chicken carcasses and their susceptibility to antimicrobial agents. Brazilian Journal of Microbiology, v.40, p.569-573, 2009.

FAI, A.E.C.; FIGUEIREDO, E.A.T.; VERDIN, S.E.F.; PINHEIRO, N.M.S.; BRAGA, A.R.C.; STAMFORD, T.L.M. Salmonella $s p$ e Listeria monocytogenes em presunto suíno comercializado em supermercados de Fortaleza ( $C E$, Brasil): fator de risco para a saúde pública. Ciência \& Saúde Coletiva, v.16, n.2, p.657-662, 2011.

FRANCHIN,P.R.; OGLIARI, P.J.; ANDRADE, D.F.; CHIAPINOTO, M.; LEMOS, G.; REBELATTO, M.; SILVA, I.G.; BATISTA, C.R.V. Comparision of the Bax ${ }^{\circledR}$ system with an In-house MSRV method for the detection of Salmonella in chicken carcasses and pork meat. Brazilian Journal of Microbiology, v.37, p.521-526, 2006.

FREITAS NETO, O.C.; MESQUITA, A.L.; PAIVA, J.B.; ZOTESSO, F.; BERCHIERI JÚNIOR, A. Control of Salmonella enterica serovar Enteritidis in laying hens by inactivated Salmonella Enteritidis vaccines. Brazilian Journal of Microbiology, v.39, p.390-396, 2008.

GORDON, M.A. Salmonella infections in immunocompromised adults. Journal of Infection, v.56, p.413-422, 2008.

GREIG, J.D.; RAVEL, A. Analysis of foodborne outbreak data reported internationally for source attribution. International Journal of Food Microbiology, v.130, p.77-87, 2009.

GUIBOURDENCHE, M.; ROGGENTIN, P.; MIKOLEIT, M.; FIELDS, P.I.; BOCKEMÜHL, J.; GRIMONT, P.A.D.; WEILL, F.X. Supplement 2003 e 2007 (No. 47) to the White-KauffmannLe Minor scheme. Research in Microbiology, v.161, p.26-29, 2010.

HOFER, E.; SILVA FILHO, S.J.; REIS, E.M.F. Sorovares de Salmonella isolados de matériasprimas e de ração para aves no Brasil. Pesquisa Veterinária Brasileira, v.18, n.1, p.2127, 1998.

JARADAT, Z.W.; BZIKOT, J.H.; ZAWISTOWSKI, J.; BHUNIA, A.K. Optimization of a rapid dot-blot immunoassay for detection of Salmonella enterica serovar Enteritidis in poultry products and environmental samples. Food Microbiology, v.21, p.761-769, 2004.

JENSEN, H.H.; UNNEVEHR, L.J.; GOMES, M.I. The costs of improving food safety in the meat sector. Journal of Agricultural and Applied Economics, v.30, n.1, 1998. 
KINDE, H.; READ, D.H.; ARDANS, A.; BREITMEYER, R.; BELL, D.; KUNEY, D.; CUTLER, D. Economic impact of the Salmonella enteritidis control program to the egg industry in California. Disponível em: <http://animalscience.ucdavis.edu/avian/kinde.pdf> Acesso em: $21 / 04 / 2011$

KOTTWITZ, L.B.M.; BACK, A.; LEÃO, J.A.; ALCOCER, I.; KARAN, M.; OLIVEIRA, T.C.R.M. Contaminação por Salmonella spp. em uma cadeia de produção de ovos de uma integração de postura comercial. Arquivo Brasileiro de Medicina Veterinária e Zootecnia, v.60, n.2, p.496-498, 2008.

KOTTWITZ, L.B.M.; OLIVEIRA, T.C.R.M.; ALCOCER, I.; FARAH, S.M.S.S.; ABRAHÃO, W.S.M.; RODRIGUES, D.P. Avaliação epidemiológica de surtos de salmonelose ocorridos no período de 1999 a 2008 no Estado do Paraná, Brasil. Acta Scientiarum Health Sciences, Maringá, v. 32, n. 1, p. 9-15, 2010.

LAN, Y.; WANG, S.; YIN, Y.; HOFFMANN, W.C.; ZHENG, X. Using a Surface Plasmon Resonance Biosensor for Rapid Detection of Salmonella Typhimurium in Chicken Carcass. Journal of Bionic Engineering, v.5, p.239-246, 2008.

LEANDRO, N.S.M.; OLIVEIRA, A.S.C.; GONZALES, E.; CAFÉ, M.B.; STRINGHINI, J.H.; ANDRADE, M.A. Probiótico na ração ou inoculado em ovos embrionados. 1. Desempenho de pintos de corte desafiados com Salmonella Enteritidis. Revista Brasileira de Zootecnia, v.39, n.7, p.1509-1516, 2010.

LEON-VELARDEA, C.G.; CAIA, H.Y.; LARKINA, C.; BELL-ROGERSA, P.; STEVENSB, R.W.C.; ODUMERUA, J.A. Evaluation of methods for the identification of Salmonella enteric serotype Typhimurium DT104 from poultry environmental samples. Journal of Microbiological Methods, v.58, p.79- 86, 2004.

LIU, W.; LIU, B.; ZHU, X.; YU, S.; SHI, X. Diversity of Salmonella isolates using serotyping and multilocus sequence typing. Food Microbiology, v.11, 2011.

LÖFSTRÖMA, C.; HANSEN, F.; HOORFAR, J. Validation of a 20-h real-time PCR method for screening of Salmonella in poultry faecal samples. Veterinary Microbiology, v.144, p.511-514, 2010.

LOPES, M.; GALHARDO, J.A.; OLIVEIRA, J.T.; TAMANINI, R.; SANCHES, S.F.; MULLER, E.E. Pesquisa de Salmonella spp. e microrganismos indicadores em carcaças de frango e água de tanques de pré-resfriamento em abatedouro de aves. Semina: Ciências Agrárias, Londrina, v.28, n.3, p.465-476, 2007.

MARTELLI, F.; DAVIES, R.H. Salmonella serovars isolated from table eggs: An overview. Food Research International, 2011.

MIZUMOTO, N.; SASAI, K.; TANI, H.; BABA, E. Specific adhesion and invasion of Salmonella Enteritidis in the vagina of laying hens. Veterinary Microbiology, v.111, p.99-105, 2005

MOURA, A.M.G. Avaliação da eficácia de bacterinas comerciais no controle da infecção por Salmonella Enteritidis em galinhas de postura comercial. 2007. Jaboticabal. Dissertação (Mestrado em Medicina Veterinária) - Curso de Pós-graduação em Medicina Veterinária, Universidade Estadual Paulista.

OLIVEIRA, G.H.; BERCHIERI JUNIOR, A.; BARROW, P.A. Prevention of Salmonella infection by contact using intestinal flora of adult birds and/or a mixture of organic acids. G.H. de Oliveira et al. Brazilian Journal of Microbiology, v.31, p.116-120, 2000.

PENHA, G.A.; SUZUKI, E.Y.; UEDA, F.S.; PERES PEREIRA, R. E. Diagnóstico da salmonelose e sua importância para a avicultura: Revisão de literatura. Revista Científica Eletrônica de Medicina Veterinária, n.10, 2008.

PICKERING, L.K.; PETER, G. 2000 Red Book - Relato do Comitê de Doenças Infecciosas. 25 ed. Elk Grove Village, il. American Academy of Pediatrics, 2000, 160p. 
PINTO, A.T.; MENDONÇA, A.D.; SILVA, E.N. Isolated or associated experimental contamination of albumen and egg yolk for Salmonella Enteritidis and Escherichia coli influence of temperature and storage time. Arquivo Brasileiro de Medicina Veterinária e Zootecnia, v.61, n.1, p.128-134, 2009.

PINTO, A.T.; SILVA, E.N. Ensaios de penetração de Salmonella Enteritidis em ovos de galinha com diferentes qualidades de casca, submetidos ou não a lavagem industrial e a duas temperaturas de armazenagem. Arquivo Brasileiro de Medicina Veterinária e Zootecnia, v.61, n.5, p.1196-1202, 2009.

RAGHIANTE, F.; ROCHA, T.S.; ROSSI, D.A.; SILVA, P.L. Penetration time of Salmonella Heidelberg through shells of white and brown commercial eggs. Brazilian Journal of Poultry Science, v.12, n.4, p.273 - 277, 2010.

RALL, V.L.M.; RALL, R.; ARAGON, L.C.; SILVA, M.G. Evaluation of three enrichment broths and five plating media for Salmonella detection in poultry. Brazilian Journal of Microbiology, v.36, p.147-150, 2005.

RIBEIRO, A.M.L.; VOGT, L.K.; CANAL, C.W.; CARDOSO, M.R.I.; LABRES, R.V.; STRECK, A.F.; BESSA, M.C. Effects of prebiotics and probiotics on the colonization and immune response of broiler chickens challenged with Salmonella Enteritidis. Brazilian Journal of Poultry Science, v.9, n.3, p.193 - 200, 2007.

RIBEIRO, A.R.; KELLERMANN, A.; SANTOS, L.R.; NASCIMENTO, V.P. Resistência antimicrobiana em Salmonella Enteritidis isoladas de amostras clínicas e ambientais de frangos de corte e matrizes pesadas. Arquivo Brasileiro de Medicina Veterinária e Zootecnia, v.60, n.5, p.1259-1262, 2008.

ROITT, I. M.; MALE, D.K.; BROSTOFF, J. Imunologia. 6. ed. São Paulo: Manole, 2003, 481p.

ROSSI, A.A.; PADILHA, M.T.S.; SANTOS, I.I.; PADILHA, J.C.F. Uso de probiótiocos na prevenção de salmoneloses em frangos de corte. Ciência e Agrotecnologia, Lavras, v.31, n.4, p.1207-1211, 2007.

RUBINO, J.R. The Economic Impact of Human Salmonella Infection, Clinical Microbiology Newsletter, v.19, n.4, p.25-32, 1997.

SADEYEN, J.; TROTEREAU, J.; VELGE, P.; MARLY, J.; BEAUMONT, C.; BARROW, P.A.; BUMSTEAD, N.; LALMANACH, A. Salmonella carrier state in chicken: comparison of expression of immune response genes between susceptible and resistant animals. Microbes and Infection, v.6, p.1278-1286, 2004.

SANTOS, R.L.; ZHANG, S.; TSOLISA, R.M.; KINGSLEY, R.A.; ADAMS, L.G.; BÄUMLER, A.J. Animal models of Salmonella infections: enteritis versus typhoid fever. Microbes and Infection, v.3, p.1335-1344, 2001.

SANTURIO, J.M.; SANTURIO, D.F.; POZZATTI, P.; MORAES, C.; FRANCHIN, P.R.; ALVES, S.H. Atividade antimicrobiana dos óleos essenciais de orégano, tomilho e canela frente a sorovares de Salmonella enterica de origem avícola. Ciência Rural, Santa Maria, v.37, n.3, p.803-808. 2007.

SHAUGHNESSY, R.G,; MEADE, K.G.; CAHALANE, S.; ALLAN, B.; REIMAN, C.; CALLANAN, J.J.; FARRELLY, C. Innate immune gene expression differentiates the early avian intestinal response between Salmonella and Campylobacter. Veterinary Immunology and Immunopathology, v.132, p.191-198, 2009.

SHEELA, R.R.; BABU, U.; MU, J.; ELANKUMARAN, S.; BAUTISTA, D.A.; RAYBOURNE, R.B.; HECKERT, R.A.; SONG, W. Immune Responses against Salmonella enterica Serovar Enteritidis Infection in Virally Immunosuppressed Chickens. Clinical and Diagnostic Laboratory Immunology, v.10, n.4, p. 670-679, 2003. 
SHINOHARA, N.K.S.; BARROS, V.B.; JIMENEZ, S.M.C.; MACHADO, E.C.L.; DUTRA, R.A.F.; LIMA FILHO, J.L. Salmonella spp., importante agente patogênico veiculado em alimentos. Ciência \& Saúde Coletiva, v.13, n.5, p.1675-1683, 2008.

SILVA, M.A.; MARVULO, M.F.V.; MOTA, R.A.; SILVA, J.C.R. A importância da ordem Ciconiiformes na cadeia epidemiológica de Salmonella spp. para a saúde pública e a conservação da diversidade biológica. Pesquisa Veterinária Brasileira, v.30, n.7, p.573$580,2010$.

SONCINI, R. A. Controle de Salmonella enteritidis na avicultura. Disponível em: <http://www.cnpsa.embrapa.br/sgc/sgc_publicacoes/anais0204_bsa_soncini.pdf> Acesso em: 19/04/2011.

SOUZA, R.B.; MAGNANI, M.; OLIVEIRA, T.C.R.M. Mecanismos de resistência às quinolonas em Salmonella spp. Semina: Ciências Agrárias, Londrina, v.31, n.2, p.413-428, 2010

STERZO, E.V.; VARZONE, J.R.M.; FERRARI, R. Salmoneloses aviárias. Ensaios e Ciência: Ciências Biológicas, Agrárias e da Saúde, v.12, n.2, p.129-138, 2008.

TAHERGORABI, R.; MATAK, K.E.; JACZYNSKI, J. Application of electron beam to inactivate Salmonella in food: Recent developments. Food Research International, 2011

TESSARI, E.N.C.; CARDOSO, A.L.S.P.; CASTRO, A.G.M.; ZANATTA, G.F.; KANASHIRO, A.M.I. Incidência de Salmonella spp. em pintos de corte recém-nascidos. Arquivos do Instituto Biológico, São Paulo, v.70, n.3, p.279-281, 2003.

TESSARI, E.N.C.; CARDOSO, A.L.S.P.; KANASHIRO, A.M.I.; STOPPA, G.F.Z.; LUCIANO, R.L.; CASTRO, A.G.M. Ocorrência de Salmonella spp. em carcaças de frangos industrialmente processadas, procedentes de explorações industriais do Estado de São Paulo, Brasil. Ciência Rural, Santa Maria, v.38, n.9, p.2557-2560, 2008.

VON RÜCKERT, D.A.S.; PINTO, P.S.A.; SANTOS, B.M.; MOREIRA, M.A.S.; RODRIGUES, A.C.A. Pontos críticos de controle de Salmonella spp. no abate de frangos. Arquivo Brasileiro de Medicina Veterinária e Zootecnia, v.61, n.2, p.326-330, 2009.

WIGLEY, P. Genetic resistance to Salmonella infection in domestic animals. Research in Veterinary Science, v.76, p.165-169, 2004.

WIGLEY, P.; HULME, S.; ROTHWELL, L.; BUMSTEAD, N.; KAISER, P.; BARROW, P. Macrophages isolated from chickens genetically resistant or susceptible to systemic salmonellosis show magnitudinal and temporal differential expression of cytokines and chemokines following Salmonella enterica challenge. Infection and Immunity, v.74, n.2, p. $1425-1430,2006$.

WIGLEY, P.; JONESA, M.A.; BARROW, P.A. Salmonella enterica serovar Pullorum requires the Salmonella pathogenicity island 2 type III secretion system for virulence and carriage in the chicken. Avian Pathology, v.31, p.501- 506, 2002.

WRAY, C.; WRAY, A. Salmonella in Domestic Animals. Wallingford: CABI Publishing, 2003, $463 \mathrm{p}$.

YAN, S.S.; PENDRAK, M.L.; ABELA-RIDDER, B.; PUNDERSON, J.W.; FEDORKO, D.P.; FOLEY, S.L. An overview of Salmonella typing public health perspectives. Clinical and Applied Immunology Reviews, v.4, p.189-204, 2003.

YILDIRIM, Y.; GONULALAN, Z.; PAMUK, S.; ERTAS, N. Incidence and antibiotic resistance of Salmonella spp. on raw chicken carcasses. Food Research International, v.44, p.725728, 2011.

ZANCAN, F.T.; BERCHIERI JUNIOR, A.; FERNANDES, S.A.; GAMA, N.M.S.Q. Salmonella spp investigation in transport boxes of day-old birds. Brazilian Journal of Microbiology, v.31, p.230-232, 2000. 